\title{
Editorial \\ Multiscale Innovative Materials and Structures (MIMS)
}

\author{
Raffaele Barretta $^{1, *(\mathbb{D})}$, Domenico De Tommasi ${ }^{2, *(\mathbb{D})}$ and Fernando Fraternali ${ }^{3, *(D)}$ \\ 1 Department of Structures for Engineering and Architecture, University of Naples Federico II, Via Claudio 21, \\ 80125 Naples, Italy \\ 2 Department of Civil, Environmental, Land, Construction and Chemistry, Polytechnic University of Bari, \\ Via Edoardo Orabona 4, 70125 Bari, Italy \\ 3 Department of Civil Engineering, University of Salerno, Via Giovanni Paolo II, 132, 84084 Fisciano, Italy \\ * Correspondence: rabarret@unina.it (R.B.); domenico.detommasi@poliba.it (D.D.T.); f.fraternali@unisa.it (F.F.)
}

check for

updates

Citation: Barretta, R.; De Tommasi,

D.; Fraternali, F. Multiscale

Innovative Materials and Structures (MIMS). Nanomaterials 2022, 12, 96.

https://doi.org/10.3390/

nano12010096

Received: 30 November 2021

Accepted: 17 December 2021

Published: 29 December 2021

Publisher's Note: MDPI stays neutral with regard to jurisdictional claims in published maps and institutional affiliations.

Copyright: (c) 2021 by the authors. Licensee MDPI, Basel, Switzerland This article is an open access article distributed under the terms and conditions of the Creative Commons Attribution (CC BY) license (https:// creativecommons.org/licenses/by/ $4.0 /)$.
Increasing attention is growing towards advanced multiscale metamaterials and nanostructures, due to recent developments in nanoscience and nanotechnology. Smart nanoscale systems with unconventional features are attractive subjects for many applications, such as electronic, optical and magnetic devices, involved in many areas such as aerospace and mechanical engineering, medicine, biology and sound and heat control. The modeling, characterization and synthesis of innovative materials and structures are, thus, needed to explore new challenging scientific applications.

The Special Issue (SI) Multiscale Innovative Materials and Structures provides new insights concerning the modeling and realization of advanced nano-reinforced materials, carbon nanotube-based systems, tensegrity structures, periodic lattices and multiscale composites. Theoretical and experimental outcomes collected in the SI provide original and significant contributions in the field of nano-composites, nano-systems and nano-devices.

The first work of the SI [1] deals with the functionalization of multi-walled carbon nanotubes, showing the effects of different conditions and milling processes on thermal and electrical conductivity. Another challenging topic regarding advanced sensing applications is explored in [2], where hybrid carbon nanotubes are employed to develop a self-sensing cementitious stabilized sand by virtue of the piezo-resistivity principle. Advancements in nonlocal continuum field theories are given in [3], where an effective model of a nonlocal foundation is presented, providing an accurate and well-posed displacement-driven formulation in modeling soil-structure interactions. New developments in the framework of non-Newtonian rheology are provided in [4]. Notably, a multi-relaxation time lattice Boltzmann scheme coupled with an immersed boundary technique is adopted to describe the evolution of a non-Newtonian fluid. In the modeling of advanced materials, a growing interest is aiming towards nanocomposites due to their special features such as strength and toughness. Fiber-reinforced concrete enhanced with nanofillers is investigated in [5], where the structural response is predicted by adopting a diffuse cohesive interface approach. The potentiality of tensegrity structures for the optimal design of next-generation biomimetic fibers is investigated in [6], where a tensegrity model of spider dragline silk is established. The model can efficiently reproduce phenomena such as the Poisson effect, a tensile stress-strain response and fiber toughness. Exceptional properties of cellulose nanofiber are extensively studied in [7], enlightening the effects of the use of citric acid for hydrothermal carbonization. The effects of acetone rinsing on the thermal stability and surface area of hydrochars are also investigated. New insights on the modeling and fabrication of tensegrity metamaterials are provided in [8], where unconventional static and dynamical mechanical behaviors of bistable lattices with a tensegrity architecture and nanoscale features are deeply examined. The last paper of the SI [9] is a comprehensive review about nanocrystalline soft magnetic iron-based materials based on $\mathrm{Fe}-\mathrm{Si}-\mathrm{B}$ doped with various chemical elements. All steps from realization to application are explored with an in-depth analysis of physical processes occurring at different stages. 
It is our hope that the works collected in Multiscale Innovative Materials and Structures will provide scientific community with novel and significant contributions to the topic.

Author Contributions: All the authors equally contributed to the review of the results of the SI and to the writing of this editorial article. All authors have read and agreed to the published version of the manuscript.

Funding: This research was funded by the Italian Ministry of University and Research (MUR) under the PRIN 2017 Grant 2017J4EAYB.

Informed Consent Statement: Not applicable.

Conflicts of Interest: The authors declare no conflict of interest.

\section{References}

1. Tserengombo, B.; Jeong, H.; Dolgor, E.; Delgado, A.; Kim, S. Effects of Functionalization in Different Conditions and Ball Milling on the Dispersion and Thermal and Electrical Conductivity of MWCNTs in Aqueous Solution. Nanomaterials 2021, 11, 1323. [CrossRef] [PubMed]

2. Abedi, M.; Fangueiro, R.; Correia, A.G. Development of a Novel Multifunctional Cementitious-Based Geocomposite by the Contribution of CNT and GNP. Nanomaterials 2021, 11, 961. [CrossRef] [PubMed]

3. Vaccaro, M.S.; Pinnola, F.P.; Marotti De Sciarra, F.; Barretta, R. Elastostatics of Bernoulli-Euler Beams Resting on DisplacementDriven Nonlocal Foundation. Nanomaterials 2021, 11, 573. [CrossRef] [PubMed]

4. Coclite, A.; Coclite, G.M.; De Tommasi, D. Capsules Rheology in Carreau-Yasuda Fluids. Nanomaterials 2020, 10, 2190. [CrossRef] [PubMed]

5. De Maio, U.; Fantuzzi, N.; Greco, F.; Leonetti, L.; Pranno, A. Failure Analysis of Ultra High-Performance Fiber-Reinforced Concrete Structures Enhanced with Nanomaterials by Using a Diffuse Cohesive Interface Approach. Nanomaterials 2020, 10, 1792. [CrossRef] [PubMed]

6. Fraternali, F.; Stehling, N.; Amendola, A.; Tiban Anrango, B.A.; Holland, C.; Rodenburg, C. Tensegrity Modelling and the High Toughness of Spider Dragline Silk. Nanomaterials 2020, 10, 1510. [CrossRef] [PubMed]

7. Faradilla, R.F.; Lucia, L.; Hakovirta, M. Remarkable Physical and Thermal Properties of Hydrothermal Carbonized Nanoscale Cellulose Observed from Citric Acid Catalysis and Acetone Rinsing. Nanomaterials 2020, 10, 1049. [CrossRef] [PubMed]

8. Vangelatos, Z.; Micheletti, A.; Grigoropoulos, C.P.; Fraternali, F. Design and Testing of Bistable Lattices with Tensegrity Architecture and Nanoscale Features Fabricated by Multiphoton Lithography. Nanomaterials 2020, 10, 652. [CrossRef] [PubMed]

9. Tsepelev, V.S.; Starodubtsev, Y.N. Nanocrystalline Soft Magnetic Iron-Based Materials from Liquid State to Ready Product. Nanomaterials 2021, 11, 108. [CrossRef] [PubMed] 